\title{
Shedding light on restoring respiratory function after spinal cord injury
}

\section{Warren J. Alilain and Jerry Silver*}

Department of Neurosciences, Case Western Reserve University School of Medicine, Cleveland, OH, USA

\section{Edited by:}

William Wisden, Imperial College, UK

Reviewed by:

Melissa R. Andrews,

University of Cambridge, UK

Dena Howland, University of Florida,

USA

William Wisden, Imperial College, UK

*Correspondence:

Jerry Silver, Department of

Neurosciences, Case Western Reserve

University School of Medicine, Room

E-658, 2109 Adelbert Road, Cleveland,

$\mathrm{OH} 44106$, USA.

e-mail: jxs10@case.edu
Loss of respiratory function is one of the leading causes of death following spinal cord injury. Because of this, much work has been done in studying ways to restore respiratory function following spinal cord injury (SCl) - including pharmacological and regeneration strategies. With the emergence of new and powerful tools from molecular neuroscience, new therapeutically relevant alternatives to these approaches have become available, including expression of light sensitive proteins called channelrhodopsins. In this article we briefly review the history of various attempts to restore breathing after $\mathrm{C} 2$ hemisection, and focus on our recent work using the activation of light sensitive channels to restore respiratory function after experimental SCl. We also discuss how such light-induced activity can help shed light on the inner workings of the central nervous system respiratory circuitry that controls diaphragmatic function.

Keywords: C2 hemisection, spinal cord injury, plasticity, regeneration, respiration, phrenic nucleus, channelrhodopsin, optogenetics
Trauma at the cervical level is one of the most common types of spinal cord injury (SCI) (National Spinal Cord Injury Statistical Center, 2009). Injuries at this level are particularly devastating since this results in disruption of the bulbospinal projections to the phrenic nucleus (PN), which is composed of motor neurons that directly innervate the diaphragm. Unfortunately, high cervical lesions of the cord oftentimes lead to paralysis of the diaphragm and dependence on mechanical ventilation for survival.

In the laboratory, the model of choice for investigating cervical SCI and its resulting respiratory deficits has been the $\mathrm{C} 2$ hemisection. In this model the cervical SC is exposed and hemisected from the midline all the way to the lateral most aspect of the cord. This results in unilateral transection of the descending respiratory pathways and paralysis of the ipsilateral hemidiaphragm (Figure 1) (Moreno et al., 1992). The animal is still able to survive without use of a ventilator since the contralateral hemidiaphragm is still active. From this point, injury-induced physiological and neuroanatomical changes in the animal can be observed and methods to restore hemidiaphragmatic function can be investigated.

\section{CNS RESPIRATORY CIRCUITRY AND THE CROSSED PHRENIC PHENOMENON}

The PN is located at the caudal end of C3 to the rostral most part of the C6 level of the spinal cord in the rat (Goshgarian and Rafols, 1984). Phrenic motor neurons (PMNs) are organized tightly in a cylindrically shaped nucleus and for the most part, the dendrites travel in a rostral/caudal direction (Furicchia and Goshgarian, 1987). A variety of different inputs, which include those from glutamatergic, GABAergic, serotonergic and norepinephrine neurons innervate the PMNs (Zhan et al., 1989; Liu et al., 1990; McCrimmon et al., 1989; Chitravanshi and Sapru, 1996).

Generation of the frequency and rhythm of breathing comes from supraspinal centers, in particular, the pre-Botzinger complex; and the source of the glutamatergic inspiratory drive is from the rostral ventral respiratory group (RVRG) located in the medulla (Figure 1) (Smith et al., 1991; Moreno et al., 1992; Chitravanshi and Sapru, 1996). The left and right RVRG have axons that decussate in the medulla, travel primarily in the ventrolateral funiculi, and project to the ipsilateral and contralateral phrenic nuclei (Figure 1) (Ellenberger and Feldman, 1988). These are the respiratory pathways which can be disrupted following cervical injury.

As early as 1895 Porter showed that a hemisection of these pathways would lead to paralysis of the ipsilateral hemidiaphragm. However, he also demonstrated that if the contralateral phrenic nerve was also transected, the initially paralyzed hemidiaphragm would become rapidly active again. But now the hemidiaphragm ipsilateral to the phrenic nerve transection became paralyzed. This was termed the "crossed phrenic phenomenon". Porter later determined that the anatomical substrate behind this recovery was a previously unknown respiratory pathway that crosses the midline at the level of the phrenic nuclei-essentially bypassing the lesion (Figure 1) (Porter, 1895, for an extensive review please read Goshgarian, 2003). This pathway was deemed latent or ineffective because although the pathway to the PN ipsilateral to the hemisection remained intact it was not active or being physiologically expressed in the absence of phrenicotomy. Since then, much work has been done in trying to activate this latent pathway to restore function without having to transect the contralateral phrenic nerve.

\section{RESTORING FUNCTION AFTER EXPERIMENTAL CERVICAL INJURY}

The physiological mechanism behind the crossed phrenic phenomenon and expression of the latent crossed phrenic pathway (CPP) is an increase in central drive due to the resulting asphyxiation produced by the contralateral phrenicotomy (Lewis and Brookheart, 1951). It was further demonstrated that there is a direct relationship between the amount of central respiratory drive and the expression of the CPP and hemidiaphragmatic recovery (Lewis 


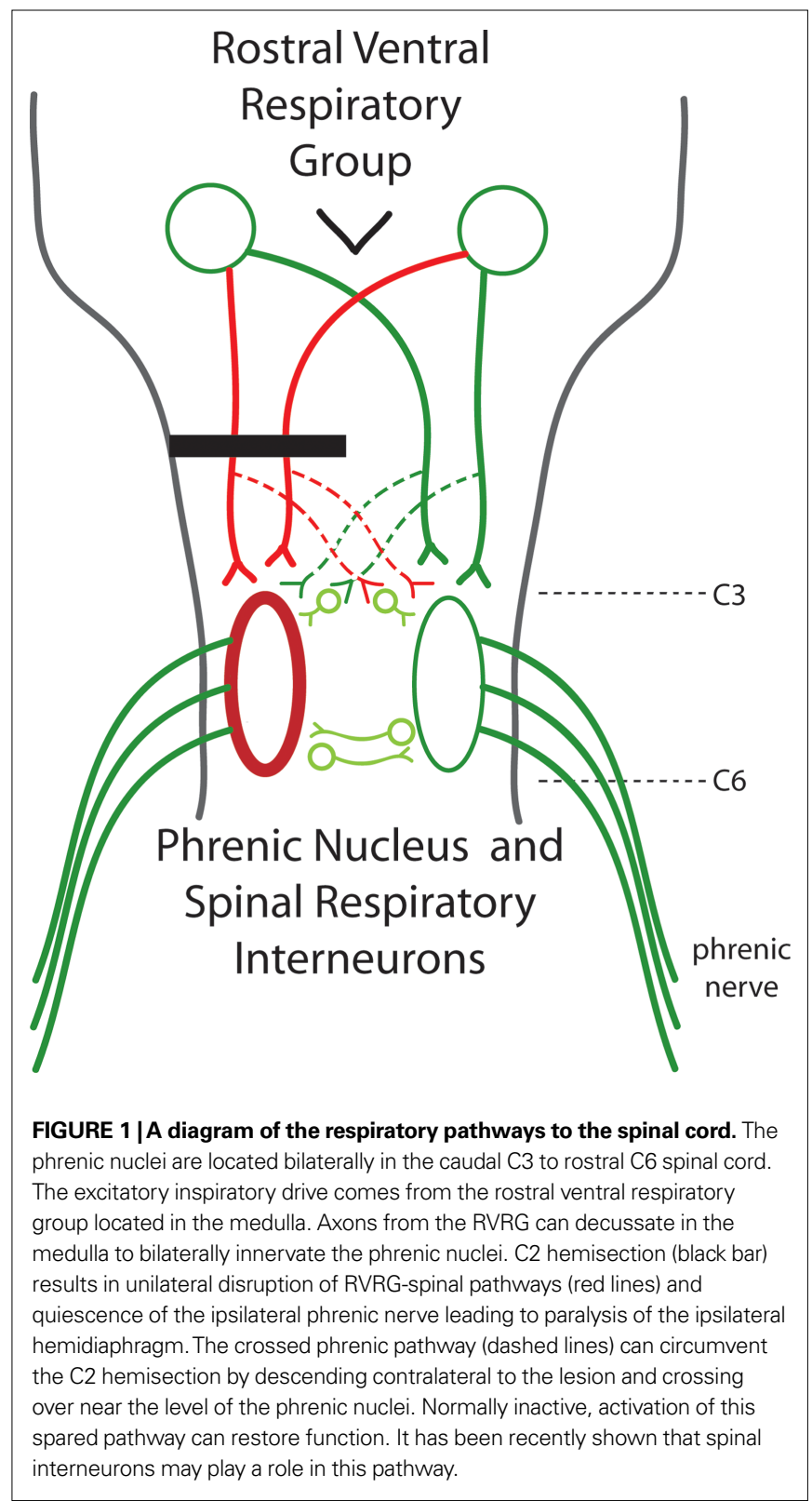

and Brookheart, 1951). With this in mind, it was hypothesized that pharmacological intervention which can increase central respiratory drive might be a potential way to induce recovery of the ipsilateral hemidiaphragm following C2 hemisection - without contralateral phrenicotomy. One such possible treatment comes from the family of CNS stimulants, the methylxanthines. Methylxanthines, and in particular, theophylline, have been extensively used for treatment in respiratory related diseases, including asthma (Riegelman and Jenne, 1980). Indeed, in a series of elegant experiments, Nantwi from the Goshgarian group showed that theophylline administration could induce recovery of the paralyzed hemidiaphragm acutely following C2 hemisection (Nantwi et al., 1996, 2003; Nantwi and Goshgarian, 1998a,b). This was attributed to antagonistic properties of theophylline to the adenosine receptor (Nantwi and
Goshgarian, 2002). In addition, theophylline's inhibitory affect on phosphodiesterase activity, resulting in an increase of cAMP levels, plays an important role in the restoration of hemidiaphragmatic activity (Kajana and Goshgarian, 2008).

Instead of increasing respiratory drive pharmacologically, altering oxygen content in the environment to induce physiological changes in the injured animals has also proven to restore or improve recovery following $\mathrm{C} 2$ hemisection. Alternating bouts of hypoxia separated by episodes of normoxia can increase or augment the spared synaptic inputs to the PN restoring function (Fuller et al., 2003; Golder and Mitchell, 2005; Doperalski and Fuller, 2006). The mechanism behind this recovery is derived from a form of respiratory plasticity called long term facilitation (LTF) which both acute and chronic intermittent hypoxia can induce. In short, LTF is a persistent increase in respiratory output after the last bout of hypoxia, lasting a long period of time $(>1 \mathrm{~h})$. This plasticity can manifest as an augmentation in the synaptic pathways to PMNs resulting in increased phrenic nerve activity and ventilation (Millhorn et al., 1980; Fuller et al., 2000; Mitchell et al., 2001; McGuire et al., 2003). Some of the mechanisms behind this plasticity include the activation of serotonin (5HT) and the glutamatergic NMDA receptors (Ling et al., 2001; McGuire et al., 2005; Ling, 2008).

In fact, it has been shown that 5HT and glutamate neurotransmission play important roles in respiratory plasticity and in restoring hemidiaphragmatic function following $\mathrm{C} 2$ hemisection. Depletion of 5HT by adding the 5HT synthesis inhibitor parachlorophenylalanine ( $\mathrm{p}-\mathrm{CPA}$ ) can abolish morphological changes following $\mathrm{C} 2$ hemisection associated with the crossed phrenic phenomenon, as well as, attenuate respiratory recovery (Hadley et al., 1999a,b). Administration of 5HT receptor agonists can also induce the expression of the CPP (Ling et al., 1994; Zhou et al., 2001; Zimmer and Goshgarian, 2006). Similarly, in other models of SCI which results in respiratory deficits, administration of select 5HT-R agonists can also result in improved function (Teng et al., 2003 and Choi et al., 2005). In the case of glutamate, the NMDA receptor, and in particular the $2 \mathrm{~A}$ subunit, has been implicated as a mediator of the recovery following chronic SCI including $\mathrm{C} 2$ hemisection. Upregulating the 2A subunit (NR2A) with the NMDA receptor antagonist MK-801 possibly through a process of "disuse hypersensitization" can restore function acutely (McDonald et al., 1990; Wilson et al., 1998; Alilain and Goshgarian, 2007). Chronically, the NR2A subunit is increased at the level of the PN and is correlated with the spontaneous onset of recovery (Alilain and Goshgarian, 2008). Also in these more chronic time points there is an increase of 5HT immunoreactive terminals and increased lengthening of glutamatergic terminals on PMNs in hemisected rats (Tai and Goshgarian, 1996; Tai et al., 1997; Golder and Mitchell, 2005).

While much of this work has focused on manipulation and strengthening of spared pathways to restore diaphragmatic activity after injury another, albeit elusive, therapeutic avenue exists which is the pursuit of a strategy to allow for frank regeneration of the interrupted bulbospinal axons to the phrenic motor nucleus. Indeed a significant number of laboratories in the field of SCI have focused on the regeneration of axons to denervated target nuclei, but as we will see there are the proverbial barriers to regeneration. 


\section{OBSTACLES TO THE REGENERATION OF RESPIRATORY PATHWAYS AND OVERCOMING THEM TO RESTORE FUNCTION}

For the most part, without any kind of intervention, regeneration is not possible in the adult CNS. In Ramon y Cajal's seminal studies, the first descriptions of the dystrophic non-regenerating endbulbs of transected axons were made (Cajal, 1928). What was especially remarkable was that these endbulbs were formed in the face of an injury-induced milieu of reactive astrocytes and extracellular matrix molecules, which has been termed the "glial scar" (for an extensive review, please see Silver and Miller, 2004). Only when presented with a growth permissive environment can the stymied axon begin to regenerate. One especially useful substrate that robustly permits such re-growth is a segment of the peripheral nervous system (PNS) when placed into the CNS (David and Aguayo, 1981; Houle et al., 2006). This PNS “bridge" presents an alternative avenue for axonal regeneration around the lesion in SCI models.

There have been numerous attempts to promote regeneration of respiratory pathways into a PNS bridge, including bridging a cervical injury to reinnervate the PN (Gauthier and Rasminsky, 1988; Lammari-Barreault et al., 1991; Decherchi et al., 1996; Decherchi and Gauthier, 2002; Gauthier et al., 2002). It has been shown that respiratory bulbospinal axons can readily regenerate into a peripheral nerve graft into the medulla near the area of the RVRG or ventrolaterally at the C2 spinal cord. However, there was no significant functional recovery of the ipsilateral phrenic nerve owing to inadequate penetration of axons back into the CNS resulting in a paucity of reinnervated phrenic motor neurons (Gauthier et al., 2002). Later experiments by Houle et al. (2006) showed that modification of glial scar associated proteoglycans at the end of the bridge with chondroitinase ABC (ChABC) does allow for successful penetration and reinnervation back into the CNS. Following a C3 hemisection and insertion of an autologous peripheral nerve bridge, there was robust regeneration of bulbospinal axons into and out of the graft back into the C5 spinal cord as well as innervation of ventral horn motor neurons. This mediated meaningful behavioral recovery of the affected forelimb which was abolished after cutting the bridge (Houle et al., 2006).

ChABC digests glycosaminoglycans (GAGs) of the extracellular matrix class of molecules called chondroitin sulfate proteoglycans (CSPGs) (for extensive review please read Busch and Silver, 2007). A key component of the glial scar and the perineuronal net (PNN), first described by Golgi (1893), CSPGs have a strong inhibitory influence on plasticity during development as well as regeneration (Davies et al., 1997, 1999; Lander et al., 1997; Pizzorusso et al., 2002, 2006; Massey et al., 2006). Interestingly, CSPGs are increased at the site of injury as well as in the PNN enveloping denervated target nuclei where they exert their inhibitory influence. These inhibitory effects can be partially relieved through the administration of ChABC (Bradbury et al., 2002; Steinmetz et al., 2005; Barritt et al., 2006; Houle et al., 2006; Cafferty et al., 2008). In the $\mathrm{C} 2$ hemisected animal, ChABC administration alone also breaks down injury induced increases of CSPGs in the PNN and induces recovery through enhanced sprouting of spared pathways (Alilain et al., 2006, 2007). We are now currently attempting to combine
ChABC treatment with peripheral nerve grafting to reinnervate the denervated $\mathrm{PN}$ and restore hemidicphragmatic function after C2 hemisection.

The rapid and intense growth of the glial scar and inhibitory proteoglycans of the PNN are just a few of the barriers to regeneration and sprouting of injured axons. Other potential factors which can contribute to CNS regeneration failure also include myelin inhibitors and infiltrating activated macrophages which actively retract axons (Brösamle et al., 2000; GrandPre et al., 2002; Horn et al., 2008). With all of these barriers to regeneration of supraspinal inputs after SCI, one might ask whether there might be another way to activate spinal motor neurons after injury without regeneration.

\section{CHANNEL RHODOPSIN 2 MEDIATED RETURN OF FUNCTION AFTER C2 HEMISECTION}

The algal protein Channelrhodopsin-2 (ChR2) is a light activated cation channel that has emerged as a powerful tool in neuroscience. Following expression in both mammalian and non-mammalian tissue, it can be induced by photostimulation to depolarize neurons, fire action potentials and control activity of neurons independent of any kind of pre-synaptic input (Boyden et al., 2005; Li et al., 2005; Zhang et al., 2006, 2007; Arenkiel et al., 2007; Herlitze and Landmesser, 2007). In SCI where one traumatic end result is diminished supraspinal input to motor neurons, we hypothesized that expression of ChR2 in spinal neurons and subsequent photostimulation might provide a powerful means to activate these otherwise quiescent cells and restore muscle activity. Therefore, in the $\mathrm{C} 2$ hemisection model, expression of ChR2 in the ipsilateral C3-C6 spinal cord and light stimulation could lead to a restoration of breathing activity in the fully adult animal (Alilain et al., 2008, for review please see Arenkiel and Peca, 2009).

Utilizing a sindbis virus at the same time as lesioning, approximately 600-700 neurons, including interneurons and motor neurons at the C3-C6 level of the spinal cord could be transfected to express ChR2 and GFP. Furthermore, retrograde tracing with dextran Texas red from the diaphragm revealed that phrenic motor neurons specifically expressed ChR2 as well. In the first series of experiments where we photostimulated the spinal cord, brief $1 \mathrm{~Hz}$ light stimulation (each flash of light being 0.5 s long) for about 30-60 s in duration was able to induce limited recovery. The restored activity was rhythmic and persisted even after photostimulation had ceased, but only up to 1 min after. Such brief hemidiaphragmatic activity could be restored multiple times in the same animal. In animals that received only the GFP control vector, there was no restoration in activity at all.

With these initial experiments as a starting point, we endeavored to induce a more long lasting type of recovery. In a stimulation protocol that we later termed "long light stimulation", we found that a pattern of $5 \mathrm{~min}$ baseline (no light) followed by $5 \mathrm{~min}$ of intermittent light $(0.5 \mathrm{~Hz}, 1 \mathrm{~s}$ on, $1 \mathrm{~s}$ off $)$ for at least three cycles led to a remarkable type of plasticity that eventually led to restored breathing by the initially paralyzed hemidiaphragm. After this stimulation protocol and sometimes during, a small amount of electromyographic (EMG) activity was detected in the hemidiaphragm ipsilateral to the lesion - including small but distinct bouts of activity coinciding with the pattern of breathing. This 
activity would wax and wane in intensity in a highly regular fashion. Furthermore, evidence from the bilateral EMG recordings, suggested that there were changes in the contralateral (opposite the side of the lesion) hemidiaphragm as well. As the firing intensity declined on the lesioned side, the non-lesioned side would increase in intensity, and vice versa. This oscillating pattern continued to increase until there was a storm of EMG activity. Surprisingly, once past this peak activity, what remained was restored breathing that was rhythmic and synchronous, with significant increases in the duration and amplitude of each inspiratory burst. After restoring breathing activity with long light stimulation and then allowing the animal to recover for 1 day, we found that restored diaphragm function persisted for at least $24 \mathrm{~h}$. The phenomenon of oscillating increases in activity bilaterally was independent of the injury since it could be evoked in an uninjured animal as well.

At the heart of this plasticity is the NMDA receptor, the long recognized mediator of plasticity and learning in the CNS (Seeburg et al., 1995; Tang et al., 1999). When the NMDA receptor antagonist MK-801 was applied prior to photostimulation there was no induction of the seizure-like activity and no restoration of breathing. From this set of data we hypothesized that photostimulation and subsequent depolarization is enough to relieve the NMDA receptor of the voltage sensitive $\mathrm{Mg}++$ block and allow for the influx of $\mathrm{Ca++}$ to occur, resulting in a signaling cascade that results in enhanced neurotransmission in the localized spinal region as well as super sensitivity to spared pathways, including the CPP. Taken together these experiments and observations demonstrate a capacity for spinal respiratory plasticity and adaptation that previously had been unknown or only speculated upon.

\section{INSIGHTS INTO RESPIRATORY CIRCUITRY AND PLASTICITY}

The transformation from the absence of activity in the paralyzed hemidiaphragm to the increasing waxing and waning of activity and oscillations between both sides, to rhythmic breathing activity demonstrates a remarkable form of plasticity in the adult spinal cord. It indicates a highly sophisticated level of connectivity between the two sides of the cord where one side can influence the other possibly through detection of the levels of activity. While the anatomical substrate that mediates this crossed communication is unknown, it is likely due to contralaterally projecting neurites from motor neurons and/or interneurons which were detected with GFP expression - and which are just now being described in the rodent (Figure 1) (Lane et al., 2008). What is also interesting as a possibility is that this newly described circuitry may play a role in generating a spinal respiratory central pattern generator.

\section{REFERENCES}

Alilain, W. J., and Goshgarian, H. G. (2007). MK-801 upregulates NR2A protein levels and induces functional recovery of the ipsilateral hemidiaphragm following acute $\mathrm{C} 2 \mathrm{hemisec}$ tion in adult rats. J. Spinal Cord Med. 30, 346-354.

Alilain, W.J., and Goshgarian, H.G. (2008). Glutamate receptor plasticity and activity-regulated cytoskeletal associated protein regulation in the phrenic motor

While central pattern generation has been widely studied during locomotion, a localized spinal respiratory central pattern generator has only been speculated to occur (Aoki et al., 1980; Reinoso et al., 1996). It is conceivable that with our photostimulation pattern we are only igniting the first step in a sequence of events that begins to incorporate more and more spinal neurons and circuitry (that does not necessarily have the ChR2 protein), which is akin to the induction of seizure activity in models of epilepsy (Bertram, 2007). With this recruitment and activation we can begin to see this crude and vestigial manifestation of central pattern generated respiration. Furthermore, the process by which the circuitry corrects and rights itself and produces the refined, rhythmic, and synchronous activity of normal respiratory activity - be it adaptation or learning - is incredibly fascinating and will lead to more insight of spinal cord networks.

\section{THE FUTURE}

With the tools of molecular neuroscience and the emergence of light sensitive channels and proteins, its combined potential as a therapeutic application in CNS trauma and disease is only now being uncovered. Parkinson's disease and deep brain stimulation, epilepsy, and SCI are just a few of the injury models where there is a potential use for these technologies. With SCI, these powerful applications can be used to target interneurons and denervated motor neurons in the spinal cord so that they can express light sensitive proteins to activate them; or cell bodies in both spinal and supraspinal centers whose axons are damaged or spared to induce activity dependent plasticity and enhance connectivity. (Brus-Ramer et al., 2007). Furthermore, although, as we have shown in the C2 hemisection model of SCI, both pharmacotherapy and environmental changes, i.e. intermittent hypoxia, have induced recovery of the paralyzed hemidiaphragm, the nature of these therapies have the repercussions of system-wide alterations in the animal - not just in the spinal cord. Some of these effects can be deleterious (Gozal et al., 2001; Row et al., 2002). With the tools of molecular neuroscience, this concern can become irrelevant with the use of distinct promoters and the targeting of specific neuronal populations. Finally, utilization of these techniques can help us better understand the circuitry and network properties of the spinal cord and CNS, in both injured and uninjured paradigms. We are just now beginning to appreciate the sophistication of remodeled spinal pathways and other pathways that might be spared after SCI and fully exploring its nature can only help us to restore function and hopefully improve the quality of life of the SCI community (Courtine et al., 2008; Rosenzweig et al., 2009).

Alilain, W. J., Horn, K. P., Dick, T. E., and Silver, J. (2007). Chondroitinase ABC treatment following $\mathrm{C} 2$ hemisection results in dramatically enhanced ipsilateral hemi-diaphragmatic recovery. Program No. 137.4. Neuroscience Meeting Planner. San Diego, CA. Soc Neurosci., Online.

Alilain, W. J., Li, X., Horn, K. P., Dhingra, R., Dick, T. E., Herlitze, S., and Silver, J. (2008). Lightinduced rescue of breathing after spinal cord injury. J. Neurosci. 28, 11862-11870.

Aoki, M., Mori, S., Kawahara, K., Watanabe, H., and Ebata, N. (1980). Generation of spontaneous respiratory rhythm in high spinal cats. Brain Res. 202, 51-63.

Arenkiel, B. R., and Peca, J. (2009). Using light to reinstate respiratory plasticity. J. Neurophysiol. 101, 1695-1698.

Arenkiel, B. R., Peca, J., Davison, I. G., Feliciano, C., Deisseroth, K., 
Augustine, G. J., Ehlers, M. D., and Feng, G. (2007). In vivo lightinduced activation of neural circuitry in transgenic mice expressing channelrhodopsin-2. Neuron 54, 205-218.

Barritt, A. W., Davies, M., Marchand, F., Hartley, R., Grist, J., Yip, P., McMahon, S. B., and Bradbury, E. J. (2006). Chondroitinase ABC promotes sprouting of intact and injured spinal systems after spinal cord injury. J. Neurosci. 26, 10856-10867.

Bertram, E. (2007). The relevance of kindling for human epilepsy. Epilepsia 48(Suppl. 2), 65-74.

Boyden, E. S., Zhang, F., Bamberg, E., Nagel, G., and Deisseroth, K. (2005). Millisecond-timescale, genetically targeted optical control of neural activity. Nat. Neurosci. 8, 1263-1268.

Bradbury, E. J., Moon, L. D., Popat, R. J., King, V. R., Bennett, G. S., Patel, P. N., Fawcett, J. W., and McMahon, S. B. (2002). Chondroitinase ABC promotes functional recovery after spinal cord injury. Nature 416, 636-640.

Brosamle, C., Huber, A. B., Fiedler, M., Skerra, A., and Schwab, M. E. (2000). Regeneration of lesioned corticospinal tract fibers in the adult rat induced by a recombinant, humanized IN-1 antibody fragment. J. Neurosci. 20, 8061-8068.

Brus-Ramer,M.,Carmel,J.B.,Chakrabarty, S., and Martin, J. H. (2007). Electrical stimulation of spared corticospinal axons augments connections with ipsilateral spinal motor circuits after injury. J. Neurosci. 27, 13793-13801.

Busch, S. A., and Silver, J. (2007). The role of extracellular matrix in CNS regeneration. Curr. Opin. Neurobiol. $17,120-127$.

Cafferty, W. B., Bradbury, E. J., Lidierth, M., Jones, M., Duffy, P. J., Pezet, S., and McMahon, S. B. (2008). Chondroitinase ABC-mediated plasticity of spinal sensory function. J. Neurosci. 28, 11998-12009.

Cajal, R. S. (1928). Degeneration and regeneration of the nervous system. London, Oxford University Press.

Chitravanshi, V. C., and Sapru, H. N. (1996). NMDA as well as non-NMDA receptors mediate the neurotransmission of inspiratory drive to phrenic motoneurons in the adult rat. Brain Res. 715, 104-112.

Choi, H., Liao, W. L., Newton, K. M., Onario, R.C., King,A.M., Desilets, F.C., Woodard, E. J., Eichler, M. E., Frontera, W. R., Sabharwal, S., and Teng, Y. D. (2005). J. Neurosci. 25, 4550-4559.

Courtine, G., Song, B., Roy, R. R., Zhong, H.,Herrmann,J.E.,Ao, Y., Qi, J., Edgerton, V. R., and Sofroniew, M. V. (2008). Recovery of supraspinal control of stepping via indirect propriospinal relay connections after spinal cord injury. Nat. Med. 14, 69-74.

David, S., and Aguayo, A. J. (1981). Axonal elongation into peripheral nervous system "bridges" after central nervous system injury in adult rats. Science 214 , 931-933.

Davies, S. J., Fitch, M. T., Memberg, S. P., Hall, A. K., Raisman, G., and Silver, J. (1997). Regeneration of adult axons in white matter tracts of the central nervous system. Nature 390, 680-683.

Davies, S. J., Goucher, D. R., Doller, C., and Silver, J. (1999). Robust regeneration of adult sensory axons in degenerating white matter of the adult rat spinal cord. J. Neurosci. 19, 5810-5822.

Decherchi, P., and Gauthier, P. (2002). Regeneration of acutely and chronically injured descending respiratory pathways within post-traumatic nerve grafts. Neuroscience 112, 141-152.

Decherchi,P., Lammari-Barreault, N., and Gauthier, P. (1996). Regeneration of respiratory pathways within spinal peripheral nerve grafts. Exp. Neurol. 137, 1-14.

Doperalski, N. J., and Fuller, D. D. (2006). Long-term facilitation of ipsilateral but not contralateral phrenic output after cervical spinal cord hemisection. Exp. Neurol. 200, 74-81.

Ellenberger, H. H., and Feldman, J. L. (1988). Monosynaptic transmission of respiratory drive to phrenic motoneurons from brainstem bulbospinal neurons in rats. J. Comp. Neurol. 269, 47-57.

Fuller, D. D., Bach, K. B., Baker, T. L., Kinkead, R., and Mitchell, G. S. (2000). Long term facilitation of phrenic motor output. Respir. Physiol. 121, 135-146.

Fuller,D.D., Johnson, S.M., Olson, E. B. Jr., and Mitchell, G. S. (2003). Synaptic pathways to phrenic motoneurons are enhanced by chronic intermittent hypoxia after cervical spinal cord injury. J. Neurosci. 23, 2993-3000.

Furicchia, J. V., and Goshgarian, H. G. (1987). Dendritic organization of phrenic motoneurons in the adult rat. Exp. Neurol. 96, 621-634.

Gauthier, P., and Rasminsky, M. (1988). Activity of medullary respiratory neurons regenerating axons into peripheral nerve grafts in the adult rat. Brain Res. 438, 225-236.

Gauthier, P., Rega, P., LammariBarreault, N., and Polentes, J. (2002). Functional reconnections established by central respiratory neurons regenerating axons into a nerve graft bridging the respiratory centers to the cervical spinal cord. J. Neurosci. Res. 70, 65-81.

Golder, F. J., and Mitchell, G. S. (2005). Spinal synaptic enhancement with acute intermittent hypoxia improves respiratory function after chronic cervical spinal cord injury. J. Neurosci. 25, 2925-2932.

Golgi, C. (1893). Intorno all'origine del quarto nervo cerebrale e una questione isto-fisiologica che a questo argomento si collega. Rendiconti della Reale Accademia Del Lincei. pp.433-450.

Goshgarian, H. G. (2003). The crossed phrenic phenomenon: a model for plasticity in the respiratory pathways following spinal cord injury. J. Appl. Physiol. 94, 795-810.

Goshgarian, H.G., and Rafols, J.A. (1984) The ultrastructure and synaptic architecture of phrenic motor neurons in the spinal cord of the adult rat. J. Neurocytol. 13, 85-109.

Gozal, E., Row, B. W., Schurr, A., and Gozal, D. (2001). Developmental differences in cortical and hippocampal vulnerability to intermittent hypoxia in the rat. Neurosci. Lett. 305, 197-201.

GrandPre, T., Li, S., and Strittmatter, S.M. (2002). Nogo-66 receptor antagonist peptide promotes axonal regeneration. Nature 417, 547-551.

Hadley, S. D., Walker, P. D., and Goshgarian, H. G. (1999a). Effects of the serotonin synthesis inhibitor $\mathrm{p}$-CPA on the expression of the crossed phrenic phenomenon $4 \mathrm{~h}$ following $\mathrm{C} 2$ spinal cord hemisection. Exp. Neurol. 160, 479-488.

Hadley,S.D., Walker,P.D., and Goshgarian, H. G. (1999b). Effects of serotonin inhibition on neuronal and astrocyte plasticity in the phrenic nucleus $4 \mathrm{~h}$ following $\mathrm{C} 2$ spinal cord hemisection. Exp. Neurol. 160, 433-445.

Herlitze, S., and Landmesser, L. T. (2007). New optical tools for controlling neuronal activity. Curr. Opin. Neurobiol. $17,87-94$

Horn, K. P., Busch, S.A., Hawthorne, A. L., van Rooijen, N., and Silver, J. (2008) Another barrier to regeneration in the CNS: activated macrophages induce extensive retraction of dystrophic axons through direct physical interactions. J. Neurosci. 28, 9330-9341.

Houle, J. D., Tom, V. J., Mayes, D., Wagoner, G., Phillips, N., and Silver, J. (2006). Combining an autologous peripheral nervous system "bridge" and matrix modification by chondroitinase allows robust, functional regeneration beyond a hemisection lesion of the adult rat spinal cord. J. Neurosci. 26, 7405-7415.

Kajana, S., and Goshgarian, H. G. (2008). Administration of phosphodiesterase inhibitors and an adenosine $\mathrm{Al}$ receptor antagonist induces phrenic nerve recovery in high cervical spinal cord injured rats. Exp. Neurol. 210, 671-680.

Lammari-Barreault, N., Rega, P., and Gauthier, P. (1991). Axonal regeneration from central respiratory neurons of the adult rat into peripheral nerve autografts: effects of graft location within the medulla. Neurosci. Lett. 125, 121-124.

Lander, C., Kind, P., Maleski, M., and Hockfield, S. (1997). A family of activity-dependent neuronal cellsurface chondroitin sulfate proteoglycans in cat visual cortex. J. Neurosci. 17, 1928-1939.

Lane, M. A., White, T. E., Coutts, M. A., Jones, A. L., Sandhu, M. S., Bloom, D. C., Bolser, D. C., Yates, B. J., Fuller, D. D., and Reier, P. J. (2008). Cervical prephrenic interneurons in the normal and lesioned spinal cord of the adult rat. J. Comp. Neurol. 511, 692-709.

Lewis, L. J., and Brookhart, J. M. (1951). Significance of the crossed phrenic phenomenon. Am. J. Physiol. 166, 241-254.

Li, X., Gutierrez, D. V., Hanson, M. G., Han, J., Mark, M. D., Chiel, H., Hegemann, P., Landmesser, L. T., and Herlitze, S. (2005). Fast noninvasive activation and inhibition of neural and network activity by vertebrate rhodopsin and green algae channelrhodopsin. Proc. Natl. Acad. Sci. U.S.A. 102, 17816-17821.

Ling, L. (2008). Serotonin and NMDA receptors in respiratory long-term facilitation. Respir. Physiol. Neurobiol. 164, 233-241.

Ling, L., Bach, K. B., and Mitchell, G. S. (1994). Serotonin reveals ineffective spinal pathways to contralateral phrenic motoneurons in spinally hemisected rats. Exp. Brain Res. 101, 35-43.

Ling, L., Fuller, D. D., Bach, K. B., Kinkead, R., Olson, E. B. Jr., and Mitchell, G. S. (2001). Chronic intermittent hypoxia elicits serotonindependent plasticity in the central neural control of breathing. J. Neurosci. 21, 5381-5388.

Liu, G., Feldman, J. L., and Smith, J. C. (1990). Excitatory amino acidmediated transmission of inspiratory drive to phrenic motoneurons. J. Neurophysiol. 64, 423-436.

Massey, J. M., Hubscher, C. H., Wagoner, M. R., Decker, J. A., Amps, J., Silver, J., and Onifer, S. M. (2006). Chondroitinase $\mathrm{ABC}$ digestion of the perineuronal net promotes functional collateral sprouting in the cuneate nucleus after cervical spinal cord injury. J. Neurosci. 26, 4406-4414.

McCrimmon, D. R., Smith, J. C., and Feldman, J. L. (1989). Involvement of excitatory amino acids in neurotransmission of inspiratory drive to spinal respiratory motoneurons. J. Neurosci. 9, 1910-1921.

McDonald, J. W., Silverstein, F. S., and Johnston, M. V. (1990). MK-801 
pretreatment enhances N-methyl-Daspartate-mediated brain injury and increases brain N-methyl-D-aspartate recognition site binding in rats. Neuroscience 38, 103-113.

McGuire, M., Zhang, Y., White, D. P., and Ling, L. (2003). Chronic intermittent hypoxia enhances ventilatory longterm facilitation in awake rats. J. Appl. Physiol. 95, 1499-1508.

McGuire, M., Zhang, Y., White, D. P., and Ling, L. (2005). Phrenic long-term facilitation requires NMDA receptors in the phrenic motonucleus in rats. J. Physiol. (Lond.) 567, 599-611.

Millhorn, D. E., Eldridge, F. L., and Waldrop, T. G. (1980). Prolonged stimulation of respiration by a new central neural mechanism. Respir. Physiol. 41, 87-103.

Mitchell, G. S., Baker, T. L., Nanda, S. A., Fuller,D.D.,Zabka,A.G., Hodgeman, B. A., Bavis, R.W., Mack, K. J., and Olson,E. B. Jr. (2001).Invited review:Intermittent hypoxia and respiratory plasticity. $J$. Appl. Physiol. 90, 2466-2475.

Moreno, D.E.,Yu,X. J., and Goshgarian, H. G. (1992). Identification of the axon pathways which mediate functional recovery of a paralyzed hemidiaphragm following spinal cord hemisection in the adult rat. Exp. Neurol. 116, 219-228.

Nantwi, K. D., Basura, G. J., and Goshgarian, H. G. (2003). Effects of long-term theophylline exposure on recovery of respiratory function and expression of adenosine A1 mRNA in cervical spinal cord hemisected adult rats. Exp. Neurol. 182, 232-239.

Nantwi, K. D., El-Bohy, A., and Goshgarian, H. G. (1996). Actions of systemic theophylline on hemidiaphragmatic recovery in rats following cervical spinal cord hemisection. Exp. Neurol. 140, 53-59.

Nantwi, K. D., and Goshgarian, H. G. (1998a). Effects of chronic systemic theophylline injections on recovery of hemidiaphragmatic function after cervical spinal cord injury in adult rats. Brain Res. 789, 126-129.
Nantwi, K. D., and Goshgarian, H. G. (1998b). Theophylline-induced recovery in a hemidiaphragm paralyzed by hemisection in rats: contribution of adenosine receptors. Neuropharmacology 37, 113-121.

Nantwi, K. D., and Goshgarian, H. G. (2002). Actions of specific adenosine receptor $\mathrm{A} 1$ and $\mathrm{A} 2$ agonists and antagonists in recovery of phrenic motor output following upper cervical spinal cord injury in adult rats. Clin. Exp. Pharmacol. Physiol. 29, 915-923.

National Spinal Cord Injury Statistical Center (2006). Spinal cord injury: facts and figures at a glance. J Spinal Cord Med. 29, 89-90.

Pizzorusso, T., Medini, P., Berardi, N., Chierzi, S., Fawcett, J.W., and Maffei, L. (2002). Reactivation of ocular dominance plasticity in the adult visual cortex. Science 298, 1248-1251.

Pizzorusso, T., Medini, P., Landi, S., Baldini, S., Berardi, N., and Maffei, L. (2006). Structural and functional recovery from early monocular deprivation in adult rats. Proc. Natl. Acad. Sci. U.S.A. 103, 8517-8522.

Porter, W. T. (1895). The path of the respiratory impulse from the bulb to the phrenic nuclei. J. Physiol. (Lond.) 17, 455-485.

Reinoso, M. A., Sieck, G. C., and Hubmayr, R. D. (1996). Respiratory muscle coordination in acute spinal dogs. Respir. Physiol. 104, 29-37.

Riegelman, S., and Jenne, J. W. (1980). Controlled release theophylline. Chest 78, 250-257.

Rosenzweig,E.S.,Brock,J.H.,Culbertson, M. D., Lu, P., Moseanko, R., Edgerton, V. R., Havton, L. A., and Tuszynski, M. H. (2009). Extensive spinal decussation and bilateral termination of cervical corticospinal projections in rhesus monkeys. J. Comp. Neurol. 513, 151-163.

Row, B. W., Kheirandish, L., Neville, J. J., and Gozal, D. (2002). Impaired spatial learning and hyperactivity in developing rats exposed to intermittent hypoxia. Pediatr. Res. $52,449-453$.
Seeburg, P. H., Burnashev, N., Kohr, G., Kuner, T., Sprengel, R., and Monyer, $\mathrm{H}$. (1995). The NMDA receptor channel: molecular design of a coincidence detector. Recent Prog. Horm. Res. 50 19-34.

Silver, J., and Miller, J. H. (2004). Regeneration beyond the glial scar. Nat. Rev. Neurosci. 5, 146-156.

Smith,J.C., Ellenberger,H.H., Ballanyi, K., Richter, D. W., and Feldman, J. L. (1991). Pre-Botzinger complex: a brainstem region that may generate respiratory rhythm in mammals. Science 254, 726-729.

Steinmetz, M. P., Horn, K. P., Tom, V. J., Miller, J. H., Busch, S. A., Nair, D., Silver, D. J., and Silver,J. (2005). Chronic enhancement of the intrinsic growth capacity of sensory neurons combined with the degradation of inhibitory proteoglycans allows functional regeneration of sensory axons through the dorsal root entry zone in the mammalian spinal cord. J. Neurosci. 25, 8066-8076.

Tai, Q., and Goshgarian, H. G. (1996). Ultrastructural quantitative analysis of glutamatergic and GABAergic synaptic terminals in the phrenic nucleus after spinal cord injury. J. Comp. Neurol. 372, 343-355.

Tai,Q.,Palazzolo,K.L.,andGoshgarian, H. G. (1997). Synaptic plasticity of 5-hydroxytryptamine-immunoreactiveterminals in the phrenic nucleus following spinal cord injury: a quantitative electron microscopic analysis. J. Comp. Neurol. 386, 613-624.

Tang, Y. P., Shimizu, E., Dube, G. R., Rampon, C., Kerchner, G.A.,Zhuo, M., Liu, G., and Tsien, J.Z. (1999). Genetic enhancement of learning and memory in mice. Nature 401, 63-69.

Teng, Y.D., Bingaman, M., Taveira-DaSilva, A. M., Pace, P. P., Gillis, R. A., and Wrathall, J. R. (2003). J. Neurosci. 23, 4182-4189.

Wilson, M.A., Kinsman, S.L., and Johnston, M. V. (1998). Expression of NMDA receptor subunit mRNA after MK-801 treatment in neonatal rats. Brain Res. Dev. Brain Res. 109, 211-220.
Zhan, W. Z., Ellenberger, H. H., and Feldman, J.L. (1989). Monoaminergic and GABAergic terminations in phrenic nucleus of rat identified by immunohistochemical labeling. Neuroscience 31, 105-113.

Zhang, F., Wang, L. P., Boyden, E. S., and Deisseroth, K. (2006). Channelrhodopsin-2 and optical control of excitable cells. Nat. Methods 3, 785-792.

Zhang, F., Wang, L. P., Brauner, M., Liewald, J. F., Kay, K., Watzke, N., Wood, P. G., Bamberg, E., Nagel, G., Gottschalk, A., and Deisseroth, K. (2007). Multimodal fast optical interrogation of neural circuitry. Nature 446, 633-639.

Zhou, S. Y., Basura, G. J., and Goshgarian, H. G. (2001). Serotonin(2) receptors mediate respiratory recovery after cervical spinal cord hemisection in adult rats. J. Appl. Physiol. 91, 2665-2673.

Zimmer, M. B., and Goshgarian, H. G. (2006). Spinal activation of serotonin $1 \mathrm{~A}$ receptors enhances latent respiratory activity after spinal cord injury. J. Spinal Cord Med. 29, 147-155.

Conflict of Interest Statement: The authors declare that the research was conducted in the absence of any commercial or financial relationships that could be construed as a potential conflict of interest.

Received: 20 July 2009; paper pending published: 22 August 2009; accepted: 01 October 2009; published online: 30 October 2009.

Citation: Alilain WJ and Silver J (2009) Shedding light on restoring respiratory function after spinal cord injury. Front. Mol. Neurosci. 2:18. doi: 10.3389/neuro.02.018.2009

Copyright $\odot 2009$ Alilain and Silver. This is an open-access article subject to an exclusive license agreement between the authors and the Frontiers Research Foundation, which permits unrestricted use, distribution, and reproduction in any medium, provided the original authors and source are credited. 